\title{
SOME GENDER ISSUES IN EDUCATIONAL COMPUTER USE: RESULTS OF AN INTERNATIONAL COMPARATIVE SURVEY
}

\author{
Ingeborg Janssen Reinen and Tueerd Plomp \\ Centre for Applied Research on Education, University of Twente, P.O. Box 217, 7500 AE Enschede, \\ The Netherlands
}

(Received 27 January 1993; accepted 2 March 1993)

\begin{abstract}
In the framework of the Computers in Education international study of the International Association for the Evaluation of Educational Achievement (IEA), data have been collected concerning the use of computers in 21 countries. This article examines some results regarding the involvement of women in the implementation and use of computers in the educational practice of elementary, lower secondary and upper secondary education in participating countries. The results show that in many countries computer use in schools is dominated by men. Female teachers have less regard for their skills and knowledge than their male colleagues have for their own skills and knowledge. In all countries (except for the French-speaking countries) less than half of the schools had a special policy for the promotion of equal opportunities for boys and girls with regard to computer use. This school policy mostly consists of retraining a female teacher to become a computer science teacher, or a female teacher being selected as computer coordinator.
\end{abstract}

\section{INTRODUCTION}

Equal developmental opportunities for girls and boys is a self-evident element of educational policy in most countries. When computers first made their appearance in society and subsequently within the educational system, it was not surprising that policy makers also paid attention to gender equity in this context. It is a generally held opinion that at school girls and boys should have equal chances to work with computers and that the situation must be avoided in which girls perceive computer use as something typical for boys, or for students who are good in mathematics and science. Research has shown that for these courses boys generally perform better than girls [1-3].

In general girls and boys are socialized differently, which results in girls learning different roles and attitudes than boys ("gender specific socialization"[4]). Such socialization can occur among other reasons, through the behavioural input of parents and through imitation. One who can play an important role in this process of imitation is the teacher. The importance of female role models for the career perspectives and interests of female students has been demonstrated in various studies[4], although Voogt [5] states that the importance of female teachers as role models for girls is still not completely clear. It is contended here that bringing girls into contact with women who are employed in science and maths or computer literacy courses, particularly, is an important means of positively influencing the choices and performance of girls. For this reason, female teachers as potential role models will be specifically dealt with below.

Based on data from the Computers in Education (Comped) survey, this article will describe certain aspects of practice in schools in 1989, and relate them to claims which were made by earlier research and development projects. The following questions will be examined:

(i) to what degree are female role models offered to girls in the schools,

(ii) in what way do school policies take gender equity issues into account, and

(iii) to what extent are gender equity issues dealt with in the curriculum?

The concept of 'computer use' can be divided into two parts. It includes learning about the computer (for example, in computer literacy courses) as well as learning with the computer (tutorial, computer aided instruction, simulations, etc.). Within the context of this article both types will be dealt with, because in both cases the gender issue arises. 


\section{DIFFERENCES BETWEEN BOYS AND GIRLS AND SUGGESTIONS FOR CHANGE}

With regard to the differences between girls and boys (or women and men) in their use of computers, in the literature [6] a rough division is made among four different causes:

- Motivational factors such as interest in and the personal importance attached to computer use: in general, women are less positive in this respect than men [6-8]. Dam et al. [9] warn against an overly simple explanation of these differences, because men/boys often have more experience with computers; Klopper and Schleyper [4] mention three important factors that contribute to the motivation of girls: computer practice (how often they play or work with computers), computer at home and best friend (if she likes computers then the motivation of girls will be higher).

-Knowledge and skills: women are less secure about their computer skills[8] and know less about computers[10]; however, both factors may be the result of women having less experience with computers.

- Socialization experiences: the different socialization of men and women can result in stereotypical gender-specific roles [7]. Men are seen as technically oriented and interested in 'how things work', while women are seen as artistic and less involved in practical matters: this may lead to male and female teachers serving as different role models with regard to working with computers, which may, in turn, lead to the continuation of the described stereotypes. Women react more positively than men when asked about the abilities of 'women in general' as computer users and scientists, but women see themselves individually as less reliable and competent with computers than men see themselves[8]. Collis[11] calls this phenomenon the 'we can do it, but I can't' paradox.

-Differences in access: both within and outside school, girls work less with computers than boys [6,12] and women significantly less often have computers at home[10]. When the access to computers at school is examined, it appears [9] that for computer use during unscheduled periods and after school, the principle of 'first come, first served ' usually applies. This is often an indirect barrier for girls.

Sutton[12], in an analysis of the research in the 1980s in the field of gender differences in computer use, states that large differences exist in the data from different schools with regard to the participation of women. She concludes from this that schools and teachers, irrespective of the society and parental influence, can play an important role in gender inequity, especially with regard to the access to computers, motivation, and knowledge attainment of girls.

Voogt [5] analysed a number of projects which were oriented towards decreasing differences between boys and girls in the use of computers and in their participation in computer education or computer literacy. From these projects and from the limited research that was available at that time, she suggested how schools could become actively involved in decreasing such differences. The suggestions were aimed at both learning with the computer and learning about the computer. The suggestions deal with teachers, the usefulness of computer education for a future occupation, curriculum development, the formation of groups and work forms, and logistics [5, pp. 32-33].

\section{Teachers:}

-involve more female teachers in computer education, to serve as role models, whether as computer education teachers or as computer-using teachers within the existing subjects;

- make teachers more conscious of the problems concerning the differences between boys and girls.

\section{Career perspective:}

- give explicit attention to the career opportunities within the information technology sector, in part through the student counsellor;

\section{Curriculum development:}

- demonstrate many different applications of computers, particularly in introductory courses;

- do not let computer education become a hard science course, i.e. part of a physical science or mathematics course;

- the choice of the programming language: Logo appeals more to girls than BASIC does. 
Formation of groups and work forms:

the creation of peer role models, fellow pupils of both sexes who function in the class as experts, and therefore can function as role models for the other pupils;

-letting girls spend just as much time at the computer as boys;

-orienting programming education not just at the programming language itself, but more at the development of problem-solving skills;

-offering computer education in such a way that the emphasis is put on the control which pupils have over the system.

\section{School organization:}

- create rules about access to computers at school in such a way that they guarantee that girls receive proper access to them, particularly during unscheduled periods and after school time (Dam et al. [9]);

-make sure that the scheduling of computer education when offered as a free choice subject does not form an obstacle to girls.

\section{RESEARCH QUESTIONS}

In the Comped study, data were collected from schools via principals and computer coordinators, that is the person who is responsible for the coordination of the computer use in a school, and teachers. The data concerned the context in which girls and boys use computers at school. The data from this survey are particularly useful in providing a picture of the current state of affairs at the level of the teacher, curriculum development, and school organization. The following questions will be dealt with:

(1) To what degree are female role models present in the education given to girls, in the sense of female teachers who use computers (whether within computer education or within other subjects) or female computer coordinators, and to what degree do female teachers form role models equivalent to the male role models in the sense of attitude towards computers, knowlcdge and skills in the computer domain and problems which are experienced within this domain?

(2) What are the policies of the schools with respect to problems of gender equity in computer use and to what degree are they directed towards the realization of equal opportunities in computer use?

(3) Referring to Voogt's suggestions regarding school curricula [5]:

(i) is a variety of computer applications offered within the subject of computer education and/or within existing subjects?

(ii) when programming languages are taught: is a 'girl-friendly' programming language used?

(iii) to what extent is computer use within existing subjects related to mathematics or science?

\section{THE STRUCTURE OF THE COMPED STUDY}

The Computers in Education research project is a large scale international comparative study on the use of computers in education, which is being conducted under the auspices of the IEA, the International Association for the Evaluation of Educational Achievement. Twenty countries are participating in the project.

The populations in the research project were schools for primary education, lower and upper secondary education; in 1989 data were collected from schools and teachers who either did or did not use computers for instructional purposes. At the school level, principals and computer coordinators (the latter only in computer-using schools) filled in questionnaires. For the selection of teachers in secondary education, computer education teachers were chosen along with teachers of mathematics, mother tongue, and science.

The sampling was aimed at the realization of a representative sample of the educational systems in the participating countries[13]. As a first step, a sample of schools was drawn (stratified where 
relevant). The selection chance was proportional to the number of pupils per school. The selected schools were requested to submit a list of the names of the teachers of the above-mentioned subjects. Teachers, both computer users and non-computer users, were then randomly selected from these lists. For more detailed information about the design of this study as well as the international results, see Pelgrum and Plomp[13]. In the second phase of the project, data collection in 1992, data at the student level were also collected.

Table 1 contains the number of respondents from those groups and those countries which will be dealt with in this article. Because, in this context, the division between males and females is relevant, only those countries were included in which there were at least 30 female teachers and 30 male teachers in the sample. Considering the small number of computer-using teachers (of whom a relatively small proportion are women), the teachers for computer education, mathematics, sciences, and mother tongue in secondary education are combined into one category. When noteworthy differences occur, a distinction is made between the computer education teachers and teachers of other subjects.

The proportion of girls to boys in the schools in all of the countries which are considered here, in computer-using schools as well as non-computer-using schools, were roughly equal, except for some countries in upper secondary school such as India $(36 \%$ female students in using schools and $32 \%$ in non-using schools) and Poland ( $72 \%$ girls in computer-using and $74 \%$ in non-using schools).

\section{TEACHERS: ROLE MODELS FOR THE GIRLS}

With regard to the first research question, dealing with role models, two points will be examined: first, the number of women involved in computer use in the schools and, second, the type of role models the female teacher offers.

\subsection{Number of potential role models}

Table 2 contains the percentages of female principals, computer coordinators and teachers in the schools where computers are used.

A majority of female teachers is found in most countries in primary education and, in about half of the countries under study, in secondary education also while, with the exception of the U.S.A., a small, sometimes very small, percentage of schools have a female computer coordinator. One would expect that the percentage of female teachers should reflect the percentage of female computer coordinators. For many countries, a comparison of female teachers with female coordinators is not consistent with that expectation. The conclusion is that role models for computer use shows the under-representation of women. From the comparison of the percentage of female computer coordinators with the percentage of female principals (Table 2), it can be concluded that this underrepresentation is not only present in the context of computer use. Female principals occupy only a relatively small number of management positions within the schools. Portugal is the only exception.

Insight into the degree that female teachers work with computers can be obtained by examining the percentage of women in the sample of computer-using teachers (Table 3). In this context, note that percentages of female teachers in computer-using schools (Table 2) cannot be compared with the data from Table 3. When comparing the number of female teachers who work with the computer with the number of male computer users (Table 3), again the general under-representation of women appears, with the exceptions of Canada-BC, New Zealand and the U.S.A. in primary education and Portugal and the U.S.A. in lower secondary education. For upper secondary education a distinction must be made between computer education teachers and existing subject teachers. In the first group, France and the U.S.A. have a majority of females teaching while in the group of existing subject teachers, Portugal has a majority of females.

In summary, it may be concluded that in all of the countries examined here computer use in the schools is dominated by men. The numbers support the concerns of many policy makers, educational professionals and those involved in gender equity in this field, that the daily practical situations in which computers are used in schools conveys too much of a suggestion that working 


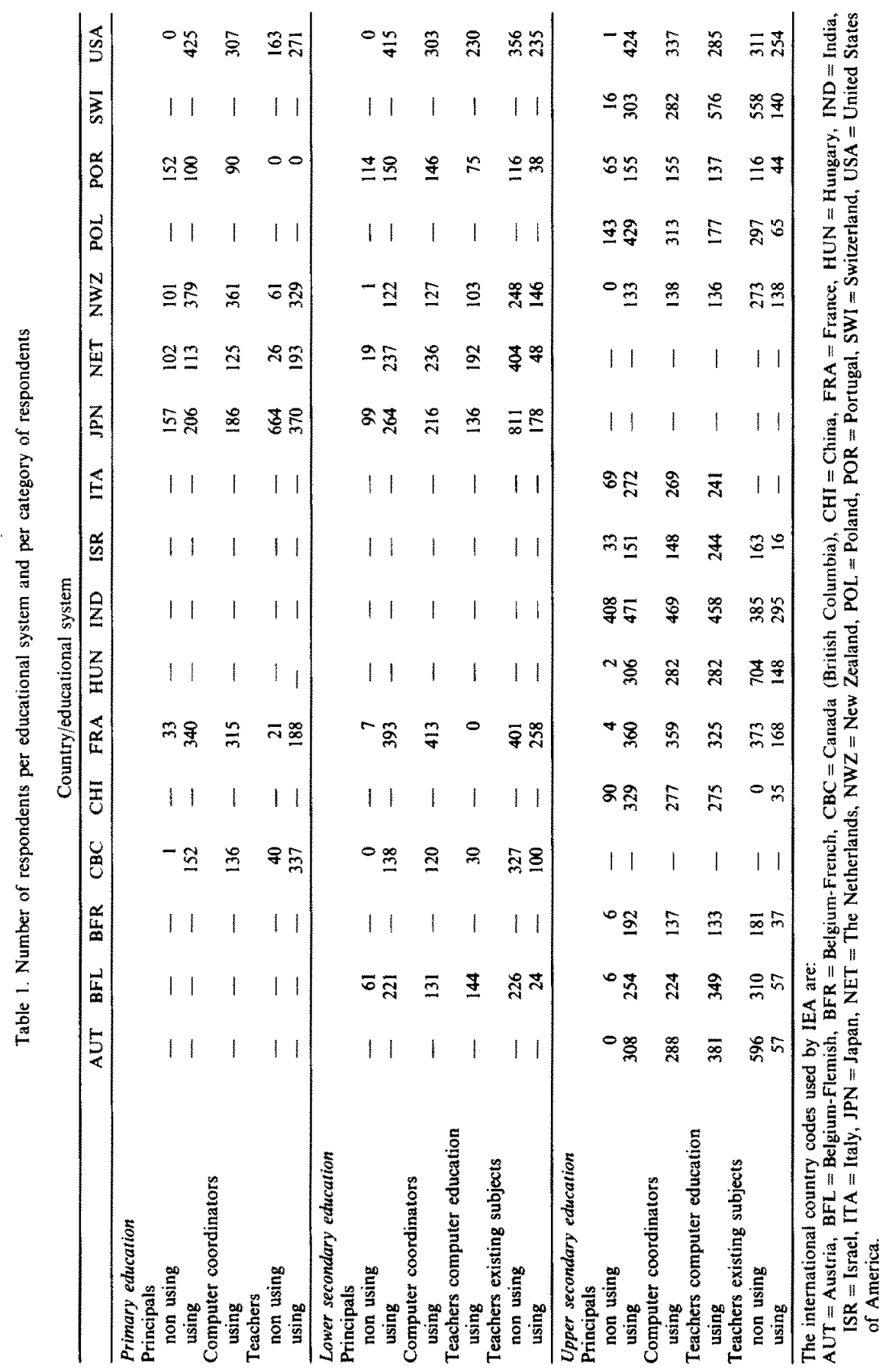


Table 2. Percentage female principals, computer coordinators (coco's) and teachers in computer using schools

Country/educational system

\begin{tabular}{|c|c|c|c|c|c|c|c|c|c|c|c|c|c|}
\hline & \multicolumn{6}{|c|}{ Primary education } & \multicolumn{7}{|c|}{ Lower secondary education } \\
\hline & $\mathrm{CBC}$ & FRA & JPN & NET & NWZ & USA & BFL & $\mathrm{CBC}$ & FRA & NET & NWZ & POR & USA \\
\hline Female principals & 17 & 44 & 5 & 6 & 17 & $m$ & 16 & 8 & 21 & 3 & 20 & 52 & $m$ \\
\hline Female coco's & 28 & $m$ & 17 & 5 & 21 & 75 & 15 & 14 & $m$ & 2 & 22 & 23 & $m$ \\
\hline Female teachers & 71 & 59 & 50 & 63 & 68 & $m$ & 50 & 37 & 60 & 28 & 48 & 65 & $m$ \\
\hline
\end{tabular}

\begin{tabular}{lcccccccccccccc}
\hline & \multicolumn{11}{c}{ Upper secondary education } \\
\cline { 2 - 16 } & AUT & BFL & BFR & CHI & FRA & HUN & IND & ISR & ITA & NWZ & POL & POR & SWI & USA \\
\hline Female principals & 15 & 16 & 14 & 8 & 18 & 21 & 27 & 19 & 19 & 21 & 32 & 54 & 7 & 13 \\
Females coco's & 12 & 16 & 17 & 14 & 18 & 24 & 25 & 36 & 27 & 15 & 35 & 23 & 3 & 45 \\
Female teachers & 44 & 48 & 54 & 48 & 46 & 57 & 46 & 55 & 57 & 50 & 68 & 64 & 29 & 47 \\
\hline
\end{tabular}

$m=$ missing $(N<50$ or missing data $>20 \%)$.

with computers is an activity for men and not for women. There are only a few exceptions to this trend.

\subsection{Types of role models}

Along with examining the number of female teachers and computer coordinators, it is also important to investigate the extent to which female teachers (either as computer education teachers or as computer users in one of the existing subjects) serve as positive role models for girls. Three aspects are relevant in this context: knowledge and skills with respect to the computer, problems which are experienced in computer use, and attitude towards the computer.

\subsection{Knowledge and skills}

Teachers who use the computer, whether within computer education or in existing subjects, need to have knowledge about computers and skills in working with computers. In this respect, the type of role model that a female teacher offers to girls can be of importance: a female teacher who possesses broad knowledge and skills with regard to computers will give a different impression to girls than a female teacher with limited knowledge and skills. Differences between men and women can be studied by examining three self-rating scales about computer knowledge and skills, which are part of the teacher questionnaire. The three scales can be characterized as follows: (i) knowledge scale: 9 questions about knowledge of hardware and software; (ii) programming scale: 5 questions about programming skills, and (iii) capability scale: 8 questions about the expertise of teachers in using the computer as an instrument, for example, in word processing and/or computer aided instruction. All questions are yes/no questions; a complete instrument is included in [13].

The results on these scales are presented in Table 4, in which a median percentage per country is given for the scores on the different scales.

It appears that at all educational levels and for all schools the male teachers' self-ratings of their knowledge and skills are higher than or equal to the female teachers' self-ratings. The data also

Table 3. Percentage females in sample of computer using teachers

Country/educational system

\begin{tabular}{|c|c|c|c|c|c|c|c|c|c|c|c|c|c|}
\hline & \multicolumn{6}{|c|}{ Primary education } & \multicolumn{7}{|c|}{ Lower secondary education } \\
\hline & $\mathrm{CBC}$ & FRA & JPN & NET & NWZ & USA & BFL & $\mathrm{CBC}$ & FRA & NET & NWZ & POR & USA \\
\hline Female teachers (total) & 53 & 36 & 22 & 21 & 50 & 80 & 32 & 33 & 35 & 15 & 41 & 61 & 55 \\
\hline Female teachers comped & - & - & - & - & - & - & 31 & 18 & - & 16 & 32 & 57 & 50 \\
\hline Female teachers ex.subj. & - & - & 一 & - & 一 & - & 33 & 37 & 35 & 9 & 48 & 69 & 59 \\
\hline
\end{tabular}

\begin{tabular}{|c|c|c|c|c|c|c|c|c|c|c|c|c|c|c|}
\hline & \multicolumn{14}{|c|}{ Upper secondary education } \\
\hline & AUT & $\mathrm{BFL}$ & BFR & $\mathrm{CHI}$ & FRA & HUN & IND & ISR & ITA & NWZ & POL & FOR & SWI & USA \\
\hline Female teachers (total) & 17 & 29 & $3 !$ & 28 & 48 & 34 & 24 & 46 & 44 & 28 & 48 & 36 & 8 & 46 \\
\hline Female teachers comped & 17 & 31 & 31 & 30 & 56 & 29 & 25 & 47 & 44 & 23 & 49 & 27 & 9 & 51 \\
\hline Female teachers ex.subj. & 18 & 16 & 30 & 11 & 33 & 43 & 21 & 40 & - & 33 & 46 & 62 & 6 & 41 \\
\hline
\end{tabular}

-data not collected.

ex.subj. The group of teachers teaching existing subjects (in this survey mathematics, science or mother tongue). 
Table 4. Country and gender median teacher scores on knowledge and skills self-rating scales (number of marked items, as percentage of total number of items per scake)

Country/educational system

\begin{tabular}{|c|c|c|c|c|c|c|c|c|c|c|c|c|c|}
\hline & \multicolumn{6}{|c|}{ Primary education } & \multicolumn{7}{|c|}{ Lower secondary education } \\
\hline & $\mathrm{CBC}$ & FRA & JPN & NET & NWZ & USA & $\mathrm{BFL}$ & $\mathrm{CBC}$ & FRA & NET & NWZ & POR & USA \\
\hline \multicolumn{14}{|c|}{ Knowledge scale } \\
\hline Males & 56 & 44 & 44 & 33 & 44 & 44 & 78 & 78 & 78 & 89 & 89 & 89 & 78 \\
\hline Females & 33 & 33 & 22 & 22 & 33 & 33 & 67 & 56 & 44 & 73 & 56 & 44 & 67 \\
\hline \multicolumn{14}{|c|}{ Programming scale } \\
\hline Males & 0 & 40 & 20 & 0 & 0 & 0 & 80 & 40 & 80 & 100 & 80 & 80 & 60 \\
\hline Females & 0 & 0 & 0 & 0 & 0 & 0 & 60 & 0 & 20 & 50 & 20 & 40 & 40 \\
\hline \multicolumn{14}{|c|}{ Capability scale } \\
\hline Males & 63 & 50 & 50 & 50 & 63 & 50 & 75 & 88 & 75 & 75 & 88 & 88 & 88 \\
\hline Females & 50 & 25 & 38 & 25 & 38 & 50 & 63 & 75 & 38 & 63 & 63 & 63 & 75 \\
\hline
\end{tabular}

\begin{tabular}{|c|c|c|c|c|c|c|c|c|c|c|c|c|c|c|}
\hline & \multicolumn{14}{|c|}{ Upper secondary education } \\
\hline & AUT & BFL & BFR & $\mathrm{CHI}$ & FRA & HUN & IND & ISR & ITA & NWZ & POL & FOR & SWI & USA \\
\hline \multicolumn{15}{|c|}{ Knowledge scale } \\
\hline Males & 100 & 100 & 100 & 67 & 89 & 78 & 67 & 89 & 100 & 89 & 78 & 100 & 100 & 89 \\
\hline Females & 89 & 89 & 89 & 56 & 78 & 67 & 67 & 78 & 89 & 78 & 78 & 67 & 78 & 78 \\
\hline \multicolumn{15}{|c|}{ Programming scale } \\
\hline Males & 100 & 100 & 100 & 100 & 100 & 100 & 100 & 100 & 100 & 100 & 100 & 100 & 100 & 80 \\
\hline Females & 100 & 100 & 100 & 80 & 60 & 100 & 80 & 100 & 100 & 60 & 80 & 60 & 90 & 60 \\
\hline \multicolumn{15}{|c|}{ Capability scale } \\
\hline Males & 88 & 88 & 88 & 75 & 75 & 75 & 63 & & 88 & 100 & 88 & 75 & 88 & 88 \\
\hline Females & 88 & 75 & 75 & 50 & 63 & 63 & 63 & 75 & 100 & 75 & 75 & 75 & 75 & 75 \\
\hline
\end{tabular}

demonstrate that the higher the educational level of teachers, the higher their self-ratings are. A noteworthy picture appears when looking at the programming scale. Whereas female teachers in both primary and lower secondary education score the lowest on the programming scale, in upper secondary education they score the highest on programming (except for France, New Zealand, Portugal and the U.S.A.). Computer education teachers give higher or equivalent ratings of their knowledge and skills compared to their colleagues in the existing subjects [13].

From the fact that women rate their knowledge and skills in a number of areas differently from men, it can be concluded that women may offer a different type of role model for pupils from male teachers. Men generally give higher ratings of their own abilities than women do on the knowledge, programming and skill scale. However, the above data are self-ratings, and it is possible that women underestimate their own knowledge and skills. With respect to the programming component, female teachers in primary and lower secondary education may provide girls with a less positive image, because they rate their own knowledge and skills in this area at a rather low level. In Section 8, programming will be treated more thoroughly.

\subsection{Problems with computer use}

The questionnaire for the teachers contained a list of 28 issues, which could each be experienced as a problem while using computers at school (see[13] for a complete overview). When performing a test for significant differences (MANOVA, $\alpha<0.05$ ), it was found that a significant difference existed between men and women in the total of experienced problems, in primary education $\left(F_{28.1573}=7.88, P<0.0005\right)$, as well as in lower secondary education $\left(F_{28.1512}=4.17, P<0.0005\right)$ and upper secondary education $\left(F_{28,5299}=10.05, P<0.0005\right)$. When testing the differences between men and women for each individual problem, a coefficient $\alpha<0.0018$ was chosen in order not to exceed the $\alpha<0.05$ for the entire questionnaire; based on Bonferroni inequalities[14, p. 135]. Using this criterion it appears that of the 28 possible comparisons (when per population all countries are taken together) the average percentages of female and male teachers differ significantly in 12 cases of primary education, in 3 cases of lower secondary education and 12 cases of upper secondary education. In just three cases of primary education the female teachers experience the problem as more serious than their male colleagues experience it; this is the case only once in lower secondary education and five times in upper secondary education. The problems which are experienced as being more serious by female teachers in primary education are (besides the category of 'other problems'): 'insufficient help for supervising computer using students', and 'problems with 
scheduling enough computer time'. In lower secondary education 'lack of teacher knowledge/ skills' was experienced more seriously by women. In upper secondary education, the problems experienced more by women are: 'insufficient peripherals available', 'difficulty with maintenance', 'teacher lacks knowledge', 'insufficient expertise to help teachers', 'insufficient technical operating assistance' and 'insufficient access for teachers' own use'.

Problems more often cited by men deal, on the one hand, with limited availability of resources such as 'lack of software' and 'lack of information about software' and, on the other hand, with the limitations of available resources such as 'limitations of computers', 'software which is not usable during lessons', 'software too difficult', 'poor quality of manuals', 'insufficient financial resources' and 'lack of support or initiatives from the school administration'.

\subsection{Attitude towards computers}

Besides problems which may be experienced in computer use it is important to determine whether female teachers differ from their male colleagues with respect to attitudes towards computer use in the classroom. In the questionnaire for teachers a number of items were included which asked for the respondent's opinion about computers, in which four conceptual scales were distinguished. Principal component analysis on the basis of the data has confirmed the classification that is included below [13]. The internationally reported reliability has been included between parentheses for each of the scales. The different scales are:

(1) educational implication of computer use (9 items, reliability approx. 0.90);

(2) social implications of computer use ( 6 items, reliability between 0.80 and 0.90 );

(3) need for training ( 5 items, reliability between 0.65 and 0.80 ); and

(4) self-confidence (4 items, reliability approx. 0.90 );

see Pelgrum and Plomp([13]) for the individual items. The results of this question is included in Table 5 .

From the data it appears that there are no great differences between female and male teachers on the different attitude scales. The high percentages on the 'training' scale show that most of the

Table 5. The average teacher scores per country on the attitude scales (number of marked items as percentage of total number of items per scale)

Country educational system

\begin{tabular}{|c|c|c|c|c|c|c|c|c|c|c|c|c|c|c|}
\hline & \multicolumn{6}{|c|}{ Primary education } & & \multicolumn{7}{|c|}{ Lower secondary education } \\
\hline & $\mathrm{CBC}$ & FRA & JPN & NET & NWZ & USA & & BFL & $\mathrm{CBC}$ & FRA & NET & NWZ & POR & USA \\
\hline \multicolumn{15}{|c|}{ Educational implications } \\
\hline Males & 72 & 48 & 66 & 47 & 72 & 72 & & 61 & 83 & 67 & 43 & 72 & 90) & 81 \\
\hline Females & 66 & 40 & 56 & $\$ 1$ & 66 & 74 & & 60 & 75 & 61 & 43 & 68 & 86 & 83 \\
\hline \multicolumn{15}{|c|}{ Social implications } \\
\hline Males & 70 & 62 & 60 & 72 & 74 & 66 & & $m$ & 77 & 75 & 73 & 70 & $m$ & 76 \\
\hline Females & 72 & 50 & 51 & 74 & 73 & 71 & & $m$ & 71 & 64 & $m$ & 73 & $m$ & 69 \\
\hline \multicolumn{15}{|c|}{ Training need } \\
\hline Males & 80 & 79 & 71 & 71 & 80 & 77 & & 85 & 78 & 81 & 78 & 76 & 92 & 85 \\
\hline Females & 80 & 73 & 60 & 63 & 83 & 79 & & 80 & 86 & 80 & 73 & 78 & 85 & 81 \\
\hline \multicolumn{15}{|c|}{ Self confidence } \\
\hline Males & 77 & 53 & 37 & 64 & 73 & 74 & & $m$ & 80 & 77 & 84 & 78 & $m$ & 82 \\
\hline \multirow[t]{3}{*}{ Females } & 68 & 46 & 26 & 57 & 68 & 72 & & $m$ & 76 & 52 & $m$ & 68 & $m$ & 76 \\
\hline & \multicolumn{14}{|c|}{ Upper secondary education } \\
\hline & AUT & BFL & BFR & $\mathrm{CHI}$ & FRA & HUN & IND & ISR & ITA & NWZ & POL & FOR & SWI & USA \\
\hline \multicolumn{15}{|c|}{ Educational implications } \\
\hline Males & 66 & 59 & 64 & 77 & 60 & 78 & 87 & 75 & 68 & 74 & 84 & 81 & 47 & 84 \\
\hline Females & 60 & 57 & 60 & 76 & 51 & 75 & 83 & 72 & 74 & 73 & 77 & 76 & 50 & 83 \\
\hline \multicolumn{15}{|c|}{ Social implications } \\
\hline Males & 66 & 79 & $m$ & 58 & 72 & 83 & 64 & $m$ & $m$ & 76 & 71 & $m$ & 59 & 78 \\
\hline Females & $m$ & $m$ & $m$ & $m$ & 62 & 85 & 58 & $m$ & $m$ & 81 & $m$ & $m$ & $m$ & 77 \\
\hline \multicolumn{15}{|c|}{ Training need } \\
\hline Males & 78 & 78 & 78 & 75 & 83 & 78 & 88 & 87 & 78 & 79 & 83 & 83 & 76 & 84 \\
\hline Females & 78 & 74 & 79 & 76 & 85 & 69 & 89 & 82 & 79 & 75 & 80 & 79 & 81 & 85 \\
\hline \multicolumn{15}{|c|}{ Self confidence } \\
\hline Males & 83 & 84 & $m$ & 53 & 75 & 62 & 62 & $m$ & $m$ & 86 & 60 & $m$ & 75 & 87 \\
\hline Females & $m$ & $m$ & $m$ & $m$ & 54 & 55 & 56 & $m$ & $m$ & 83 & $m$ & $m$ & $m$ & 76 \\
\hline
\end{tabular}

$m=$ missing $(N<30$ or missing data $>20 \%)$. 
computer-using teachers do not consider themselves to be sufficiently trained and that there is a widespread interest in further training. A multivariate test for significant differences (MANOVA, $\alpha<0.05$ ) was used to determine whether, within the total of attitude scales, there is a significant difference between men and women. For primary education, this did not appear to be the case, while for secondary education there was a significant difference $\left(F_{4.793}-10.12, P<0.0005\right.$ for lower secondary education and $F_{4,1397}=9.73, P<0.0005$ for upper secondary education). In order to study the significance of the differences in the individual attitude scales for lower secondary education, a coefficient of $\alpha<0.013$ was chosen in accordance with the Bonferroni inequity formula[14]. Based on this criterion, only the self-confidence scale demonstrated a significant difference between men and women in both lower and upper secondary education. In this case the men displayed greater self-confidence in using computers.

\section{SCHOOL ORGANIZATIONS: POLICY DIRECTED TOWARDS EQUAL OPPORTUNITY}

In many countries educational computer use is dominated by men, which underlines the importance of the extent to which schools have policies focussed at ensuring gender equity. Such policies at the school level can in principle be quite different: varying from the organization of special activities for girls, to the creation of a climate at the school in which the equal involvement of women/girls and men/boys is taken for granted, or to the stimulation of such a climate (for example, by arranging for enough female role models at the school level). Some conclusions from earlier published Comped reports[13, Chap. 6] will be summarized here.

With the exception of a number of French-speaking countries (including France), the number of principals who indicated that their schools had a special policy on gender equity was relatively low; for example, in Israel $13 \%$ of the primary school principals and $17 \%$ of the upper secondary school principals indicated having such a policy. In Japan, these figures are $14 \%$ for primary and lower secondary education and $22 \%$ for upper secondary education. From an emancipatory perspective this is a cause for concern.

In those cases in which schools did indicate having such a policy, the data indicate that the most commonly applied policy in all populations was 'training female teachers in the use of computers', and 'females are selected to supervise computer activities by students'. Of all the possible policies, there are generally two policies that are least applied: 'out-of-class time is set aside for girls-only access to computers' and 'a girls computer class or instructional group was formed'.

Thus, schools are more inclined to have a policy directed towards stimulating the availability of female role models (female teachers and coordinators), than to create special opportunities in which girls can use computers. This seems to imply that schools appear to place emphasis on female role models and, given the low numbers of female teachers as noted in Section 5, this is an important finding.

\section{CURRICULA IN THE SCHOOL: A GIRL-FRIENDLY LEARNING ENVIRONMENT?}

In the context of the school curricula, three points will be dealt with from a gender equity perspective. First, it will be examined to what extent various applications of computers are offered; subsequently, the type of programming instruction will be dealt with, and, finally, the relation of computer use with mathematics and science will be investigated.

\subsection{Type of application}

The offering of a variety of computer applications within computer education appears, as is suggested by Voogt [5], to be to the advantage of girls.

To form a picture of the variety of applications, the computer education teachers were asked to indicate the types of software which they use within the lessons. These could be drill or tutorial programs, as well as programs for learning word processing, spreadsheets, programming, drawing, simulations, or games. Considering that in primary schools, computer education is generally not 
given as a separate subject, this question was asked of all primary teachers. The average number of applications per country is given in Fig. 1. The average number of applications used is also given separately for male and female teachers.

In general, it appears that the variety of applications in each country is rather low, with the exceptions of New Zealand (in all populations), U.S.A. and The Netherlands in lower secondary education and Poland in upper secondary education. With respect to the differences between men and women, it appears that men, in general, use slightly more applications than their female

primary education

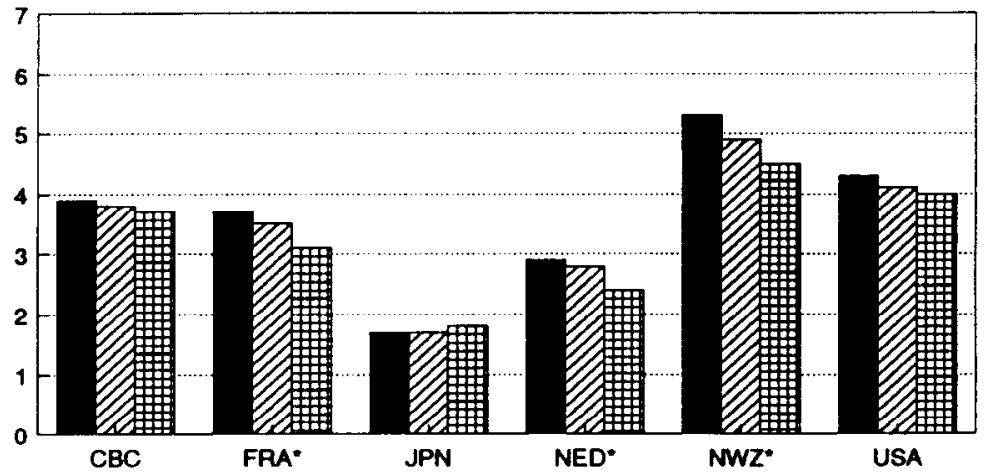

lower secondary education **

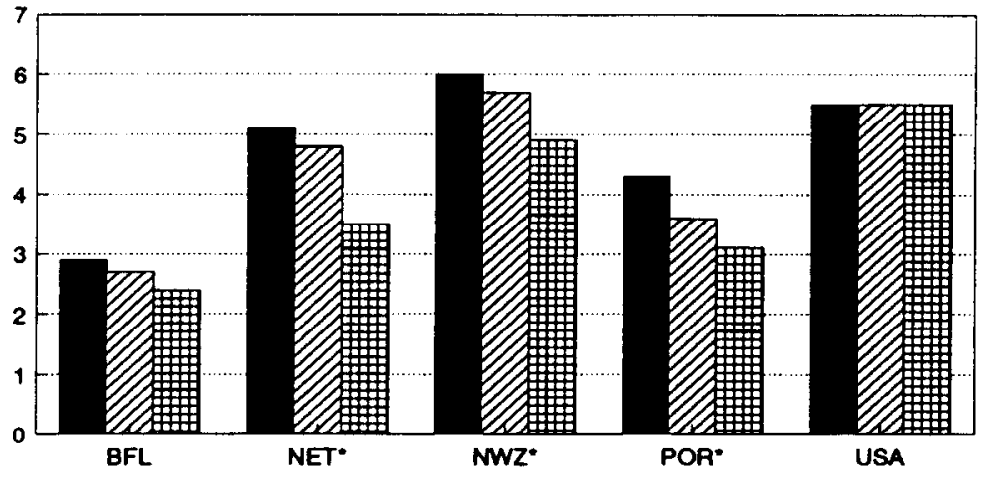

upper secondary education **

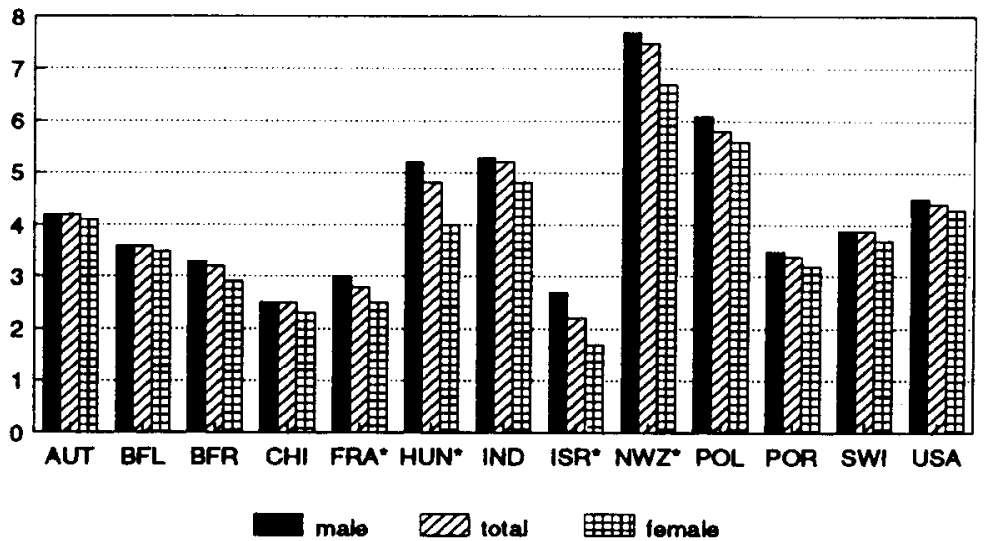

Fig. 1. Average number of applications of computers. *Significant differences $(x<0.05)$; **only those countries are included that contain at least 30 female and 30 male computer education teachers in the sample: this is a subset of countries included in this article. 
colleagues. For each country, the differences between women and men were tested for significance. As can be seen from Fig. 1, the significant data all indicate that men use more applications within computer education courses than their female colleagues.

\subsection{Programming}

One type of application in which computers are used is programming. In all countries taken together, in primary education $35 \%$ of the female teachers use programming as an application compared to $34 \%$ of the men. In lower secondary education these figures are, respectively, 64 and $67 \%$ of the computer education teachers and in upper secondary education $75 \%$ of the females and $83 \%$ of the males use programming as an application of computer use. Table 6 records the programming languages used by those teachers who indicated that programming was used as an application within their lessons.

In primary education there are three of the six countries (Canada-BC, France, and New Zealand), in which Logo is clearly more often used than any other language. Within lower secondary education, BASIC is the most frequently used programming language within computer education courses (with the exceptions of New Zealand and Portugal). The same holds for upper secondary education, although other programming languages get a more prominent place in this population. Noteworthy is the fact that in Poland Logo is the most frequently used language in upper secondary education. A cautious conclusion that can be drawn from these data is that the type of programming language that is chosen for programming instruction does not seem to be determined by the question as to which language would be more appropriate for girls. Instead, other motives seem to play a role in the choice of programming language.

\subsection{Relation with mathematics and hard science subjects}

From the suggestions of Voogt [5], it can be inferred that one advantageous condition for girls could be created when computer use is related as little as possible to mathematics and science. One argument for this is that the inequity between boys and girls in these subjects can easily be reproduced in computer education classes and when working with computers. Support for this argument can be found in the literature: boys achieve better results within mathematics and science [3,15], while it is also stated that girls' attitudes towards computers almost directly reflect their attitudes toward mathematics[16]. This transfer is partly caused by teachers who give mathematics and science also teaching the computer education classes. For computer cducation in secondary school, this aspect can only partly be examined using the Comped data. For The Netherlands, however, more detailed data have been collected. It appears that for all the countries collectively, $93 \%$ of the computer education teachers in both lower and upper secondary education also teach another subject; there are no international data which indicate what these other subjects are. In The Netherlands, $99 \%$ of the computer education respondents also teach in other subjects: $42 \%$ also teach mathematics, $14 \%$ teach science, $14 \%$ teach Dutch language, $9 \%$ give vocational training courses, $6 \%$ teach modern foreign languages, and $14 \%$ give lessons in another subject[17].

Table 6. Programming languages used as part of the curriculum

Country/educational system

\begin{tabular}{|c|c|c|c|c|c|c|c|c|c|c|c|}
\hline & \multicolumn{6}{|c|}{ Primary education } & \multicolumn{5}{|c|}{ Lower secondary education } \\
\hline & CBC & FRA & JPN & NET & NWZ & USA & BFL & NET & NWZ & POR & USA \\
\hline BASIC & 25 & 57 & 59 & 56 & 46 & 73 & 52 & 79 & 65 & 53 & 89 \\
\hline Logo & 84 & 83 & 54 & 44 & 75 & 59 & 11 & 27 & 76 & 62 & 29 \\
\hline Other languages & 9 & 1 & 2 & 5 & 11 & 9 & 48 & 11 & 6 & 6 & 4 \\
\hline
\end{tabular}

Upper secondary education

\begin{tabular}{|c|c|c|c|c|c|c|c|c|c|c|c|c|c|c|}
\hline & AUT & BFL & BFR & $\mathrm{CHI}$ & FRA & HUN & IND & ISR & ITA & NWZ & POL & POR & SWI & USA \\
\hline BASIC & 71 & 39 & 84 & 100 & 49 & 94 & 77 & 88 & 47 & 79 & 56 & 87 & 64 & 86 \\
\hline Logo & 9 & 3 & 7 & 13 & 11 & 16 & 50 & 20 & 4 & 45 & 85 & 6 & 6 & 11 \\
\hline Other languages & 47 & 75 & 38 & 5 & 62 & 24 & 31 & 26 & 91 & 43 & 40 & 38 & 46 & 31 \\
\hline
\end{tabular}


We have concluded elsewhere[18] on the basis of the Comped data that when the computer is used within existing subjects, it is usually within mathematics and sometimes within science. With respect to the relation of computer use and the so-called hard-science subjects, the cautious conclusion can be drawn that one advantageous condition for girls has not been met, namely that the computer should be coupled as little as possible with mathematics and science.

\section{CONCLUSIONS}

Research has shown that offering a female role model to girls is important. However, from the Comped data it appears that in most countries computer use at school is dominated by men; there is a general lack of female role models. When we examine the type of role model offered by women who are involved in computer use, it appears that female teachers give themselves a lower self-rating with regard to computer knowledge and skills as compared to their male colleagues. The largest differences can be observed regarding the self-ratings about programming in primary and lower secondary education. It is noteworthy that concerning the problems experienced, significant differences between men and women are due to the fact that men experience more problems than women, in most cases. Women have more problems with the organizational aspects of computer use and they experience a lack of knowledge and skills as being a problem (completely in line with the observed differences in the self-rating of knowledge and skills). The fact that men experience more problems may be due to the fact that they generally do more with the computer and therefore also experience more of the limitations. Another explanation for the observed differences could be that the threshold which women must cross in order to work with computers is high, but, in the event that they decide to use this technology, they do more to gather the necessary knowledge and skills and therefore experience fewer problems in the actual work situation. In contradiction to this explanation is the fact that women give lower self-ratings than their male colleagues for knowledge and skills; however, with regard to these data it has already been remarked that a request for self-rating is not always completely reliable, because women often underestimate their own knowledge and skills.

If we examine the attitudes of teachers towards computers, it appears that within lower and upper secondary education men have significantly greater self-confidence regarding computers.

Examination of policy concerning gender equity indicates that only in a number of Frenchspeaking countries a majority of schools have a special policy to promote equal opportunities for boys and girls. In schools which indicated that they have such a policy, it mostly comprised a re-training in computer education for female teachers and the appointment of women to supervise the computer use. This approach can be described as stimulating the availability of female role models, which, given the observed lack of female role models, would seem to be a good thing.

The extent to which the curricula of schools can be called 'girl-friendly' was investigated on a number of points. Whereas the relevant literature emphasizes the importance of using a variety of applications for the computer, the Comped data indicate that, on average, not very many different applications are used, and that female teachers generally use fewer applications within computer education courses than males do. It is not clear in this context what is meant in the literature by 'variety of applications' (how this can be measured and what is the threshold for an acceptable amount of variety).

Examination of the type of programming language that is used within computer education courses (when programming is part of the curriculum) shows that the situation in lower and upper secondary education is less advantageous for girls because BASIC is the programming language which is generally used at this school level while Logo is said to be more useful for girls. Concerning the relation of computer use with mathematics and science, a cautious first conclusion is that less advantageous conditions for girls exist in education, because computer use seems, in practice, often to be coupled to mathematics and science. These data appear to be a confirmation that computer education is stereotyped as a 'hard-science' subject. 


\section{REFERENCES}

1. Pelgrum W. J. and Plomp Tj., Second International Science Study: Beschrijving van Uitkomsten en Analyse (Second International Science Study: Description of Results and Analyses). University of Twente, Enschede, The Netherlands (1986).

2. Oost E. van, Etude in B-Mineur: een Literatuurstudie naar Verschillen Tussen Meisjes en Jongens bij de Keuze van Exacte Vakken in het Voortgezet Onderwijs (Etude in B-Minor: a Literature Study into Differences Between Boys and Girls in the Choice of Hard-science Subjects in Secondary Education). University of Twente, Enschede, The Netherlands (1986).

3. Postlethwaite T. N. and Wiley D. E., The IEA Study of Science II: Science Achievement in Twenty Three Countries. Pergamon Press, Oxford (1992).

4. Klopper D. L. and Schleyper Y. G. M., Zij Wel, Ik Ook: een Empirisch Onderzoek naar de Computerattitude van Meisjes van 10-12 Jaar (She Can, Me Too: an Empirical Study into the Computer Attitudes of Girls from 10-12 Years). Technika 10, Utrecht. The Netherlands (1990).

5. Voogt J., Vrouwen en Informatica: Meisjes in het ISI-Project (Females and Informatics: Girls in the ISI-Project). PCBB's-Hertogenbosch, The Netherlands (1987).

6. Siann G., Macleod H., Glissov P. and Durndell A., The effect of computer use on gender differences in attitudes to computers. Computers Educ. 14, 183-191 (1990).

7. Martin R., School children's attitudes towards computers as a function of gender, course subjects and availability of home computers. J. Comput. Assisted Learning 7, 187-194 (1991).

8. Temple L. and Lips H. M., Gender differences and similarities in attitudes towards computers. Computers Human Behav. 5, 215-226 (1989).

9. Dam G., Urlings M. and Volman M., Sekseverschillen in het Onderwijs: Curriculum, Didaktiek en Organisatie (Gender Differences in Education: Curriculum, Didactics and Organisation). Wolters-Noordhoff, Groningen, The Netherlands (1990).

10. Durndell A., Macleod H. and Siann G., A survey of attitudes, knowledge about and experience of computers. Computers Educ. 11, 167-175 (1987).

11. Collis B., Sex differences in secondary school students' attitudes towards computers. The Computing Teacher April, 33-36 (1985).

12. Sutton R. S., Equity and computers in the schools: a decade of research. Rev. Educational Res. 61, 475-503 (1991).

13. Pelgrum W. J. and Plomp Tj., The Use of Computers in Education Worldwide. Pergamon Press, Oxford (1991).

14. Bernstein I. H., Garbin C. P. and Teng G. K., Applied Multivariate Analysis. Springer, New York (1988).

15. Munger G. F. and Loyd B. H., Gender and attitudes towards computers and calculators: their relationship to math performance. J. Educational Computing Res. 5, 167-177 (1989).

16. Damarin S. K., Rethinking equity: an imperative for educational computing. The Computing Teacher 16, 16-18 (1989).

17. Brummelhuis ten A. C. A., Pelgrum W. J. and Plomp Tj., Informatiekunde in het voortgezet onderwijs: resultaten van een survey (Computer education secondary education: results of a survey). In Congresbundel NIOC ' 90 (Edited by Mulder F. and Crutzen C.), pp. 193-205. Kluwer, Deventer, The Netherlands.

18. Janssen Reinen I. A. M. and Plomp Tj., Gender differences in computer use with emphasis on mathematics education. Int. J. Educational Res. In press (1993). 